\title{
Life-history traits and intra-cohort divergence of clearhead icefish (Protosalanx chinensis), indicating cannibalism increased fitness
}

\author{
Fujiang Tang ${ }^{\text {Corresp., }}{ }^{1}$, Wei Liu ${ }^{1}$, Jilong Wang ${ }^{1}$, James Henne ${ }^{2}$ \\ ${ }^{1}$ Heilongjiang River Fisheries Research Institute of Chinese Academy of Fishery Sciences, Harbin, China \\ 2 United States Fish and Wildlife Service, Bears Bluff National Fish Hatchery, Wadmalaw Island, South Carolina \\ Corresponding Author: Fujiang Tang \\ Email address: tangfujiang@hrfri.ac.cn
}

Cannibalism is considered one of the causes of intra-cohort size divergence in fish and is usually believed to result in increased fitness in terms of survival and reproduction, but direct evidence of this is lacking. Population demographics of the clearhead icefish (Protosalanx chinensis) from Lake Xingkai (Khanka) were investigated for one year. Sizefrequencies exhibited a bimodal distribution from July through January, where the population diverged into an upper and a lower modal group based on size. Stomach content analysis confirmed the occurrence of cannibalism, where fish belonging to the larger, upper modal group preyed upon those of the smaller, lower modal group. We found $P$. chinensis does not spawn until all of the oocytes have reached maturity and then a single spawning event occurs although the oocytes may develope asynchronously in the ovary. Upper modal group females matured slightly earlier than those of the lower modal group, and reproductive investment was considerably greater in the upper modal group than the lower modal group. The lower modal males made up the majority of the population after the spawning period, which meant they may have few opportunities to participate in reproduction. Therefore, piscivory and cannibalism of $P$. chinensis appears to have increased fitness of the fish belonging to the upper modal group and reduced the fitness of those belonging to the lower modal group greatly. 
2 Life-history traits and intra-cohort divergence of

3 clearhead icefish(Protosalanx chinensis), indicating

4 cannibalism increased fitness

6 Fujiang Tang ${ }^{1}$, Wei Liu ${ }^{1}$, Jilong Wang ${ }^{1}$, James Henne ${ }^{2}$

$8{ }^{1}$ Heilongjiang River Fisheries Research Institute of Chinese Academy of Fishery Sciences,

9 Harbin 150070, China;

$10 \quad{ }^{2}$ Henne: United States Fish and Wildlife Service, Bears Bluff National Fish Hatchery, 7030

11 Bears Bluff Rd, Wadmalaw Island, South Carolina 29487, USA.

Corresponding Author:

Fujiang Tang

Hesong street 232, Harbin, Heilongjiang Province, 150070, China 


\section{Abstract}

Cannibalism is considered one of the causes of intra-cohort size divergence in fish and is usually believed to result in increased fitness in terms of survival and reproduction, but direct evidence of this is lacking. Population demographics of the clearhead icefish (Protosalanx chinensis) from Lake Xingkai (Khanka) were investigated for one year. Size-frequencies exhibited a bimodal distribution from July through January, where the population diverged into an upper and a lower modal group based on size. Stomach content analysis confirmed the occurrence of cannibalism, where fish belonging to the larger, upper modal group preyed upon those of the smaller, lower modal group. We found P. chinensis does not spawn until all of the oocytes have reached maturity and then a single spawning event occurs although the oocytes may develope asynchronously in the ovary. Upper modal group females matured slightly earlier than those of the lower modal group, and reproductive investment was considerably greater in the upper modal group than the lower modal group. The lower modal males made up the majority of the population after the spawning period, which meant they may have few opportunities to participate in reproduction. Therefore, piscivory and cannibalism of $P$. chinensis appears to have increased fitness of the fish belonging to the upper modal group and reduced the fitness of those belonging to the lower modal group greatly. 
43 Introduction

44 Many piscivorous fishes exhibit an ontogenetic dietary shift, transitioning from non-fish

prey to piscivory over time. An early transition to piscivory is thought to result in increased growth and reproductive fitness, decreased mortality, and therefore enhanced lifetime fitness (Werner and Gilliam 1984; Post et al. 1988). In some piscivorous fishes, young-of-the-year (YOY) intra-cohort individuals exhibited differential timing to the onset of piscivory, driving bimodal size frequency distributions and cannibalism in the age-0 group. In these cases, the larger, upper modal group (cannibals) increased their growth rate and decreased survival rate of the smaller, lower modal group (prey) (Buijse and Houthuijzen 1992; Frankiewicz et al. 1996; Post 2003; Huss et al. 2010; Heermann et al. 2013). However, direct evidence of increased reproductive fitness with the transition to piscivory is absent, although Post (2003) suggested that an early transition to piscivory may result in higher lifetime fecundity since these fish have a larger relative size and potentially more spawning opportunities in a lifetime.

The clearhead icefish, Protosalanx chinensis (Abbott 1901), is a small, pelagic, euryhaline fish species of the family Salangidae that occurs in eastern Asia (Xie and Xie 1997; Saruwatari et al. 2002). It is a short-lived semelparous fish, completing its lifecycle in about 1 year (Tang et al. 2012). Early-stage juveniles feed mainly on zooplankton, while larger individuals in young and adult-stage could switch to fish and shrimp and feed primarily on conspecifics (Tang et al. 2013).

The size-frequency of the population becomes bimodal from Month to Month (Zhu 1985).

Considering the unique biological characteristics of $P$. chinensis, we present evidence of withinpopulation size divergence, and the advantage of larger individuals over smaller individuals in 
64 survival and reproduction. These findings provide direct evidence of cannibalism, and its effects

65 on reproductive fitness of both females and males.

66

67 Methods

68

69

Study area

Lake Xingkai (Khanka) is a large shallow lake, located between China and Russia, serving as a boundary. It is connected to the Ussuri River through the Sungacha River. The northern part of the lake ( $28 \%$ of the total area) is located in China and the southern part $(72 \%$ of the total area) is located in Russia. The water level area in Khanka is variable and varies from 3940 to $5010 \mathrm{~km}^{2}$. The long-term average water level area is $4070 \mathrm{~km}^{2}$ with an average depth of $4.5 \mathrm{~m}$.

Since 2010, there has been an increase in the water level in the lake. Lake Khanka/Xingkai is one of the most important international wetlands in the world. Specimens were sampled from the northwestern part of Khanka Lake near the locality of Dangbi in China(N $45^{\circ} 15^{\prime} 49.12^{\prime \prime}$ $45^{\circ} 15^{\prime} 8.62^{\prime \prime}, \mathrm{E} 132^{\circ} 02^{\prime} 35.22^{\prime \prime}-132^{\circ} 01^{\prime} 7.73^{\prime \prime}$, Fig.1).

Sampling procedure Clearhead icefish (P. chinensis) were sampled monthly from March 2010 through March 2011 except for April 2010. Different sampling gear was used in winter and ice-free seasons to sample fish effectively. A cone trawler net (length, $3 \mathrm{~m}$; diameter, $1 \mathrm{~m}$; mesh size, 1 x $1 \mathrm{~mm}$ ) was used for sampling fish in May, while a seine net (length, $200 \mathrm{~m}$; height, $8 \mathrm{~m}$; mesh size, $2 \mathrm{x}$ $2 \mathrm{~mm}$ ) was used for sampling from June through November 2010. For each sample, the seine net 
85

was drawn parallel to the shore where the water depth was less than $1.5 \mathrm{~m}$, for about $50 \mathrm{~m}$.

Further, four gill nets (length, $30 \mathrm{~m}$; height, $1 \mathrm{~m}$; mesh size, $10 \mathrm{~mm}, 15 \mathrm{~mm}, 20 \mathrm{~mm}$, and $23 \mathrm{~mm}$ between opposite knots) positioned randomly were deployed in gangs, tied end to end perpendicular to the shore for $24 \mathrm{~h}$ per month during the freeze-up period (March 2010 and December 2010 to March 2011). For the reproductive biology and cannibalism experiments, we used two extra gill nets (length, $100 \mathrm{~m}$; height, $1 \mathrm{~m}$; mesh sizes, 20 and $23 \mathrm{~mm}$ between opposite knots) in the freeze-up period to obtain adequate samples.

Life history traits analysis

The clearhead icefish died immediately after they were captured in nets. Over 100 specimens were caught in each monthly sample and were measured for standard length (SL; to the nearest 1 $\mathrm{mm}$ ) and weight (WB; to the nearest $0.01 \mathrm{~g}$ ). A row of scales typically appears at the base of the anal fin of maturing males and the anal fin also becomes larger and wave-shaped in mid-October, but no sexual dimorphism appears before that point, so the sex of each fish was determined by examining dissected gonads. Females have a larger ovary on the left of the ventral cavity and a smaller ovary on the right side, while males have a single testis on the right of the cavity. Sex ratios were determined, and their difference from parity was tested using a binomial test. Chisquare tests were performed to assess differences in sex ratios among months.

The gonads of females sampled in November, December, and January were used to determine the gonadosomatic index (GSI) and maturity stage, and more than 50 specimens were dissected for reproductive biology studies each month. In P. chinensis, the left ovary is usually 
106

107

108

109

110

111

112

113

114

115

116

117

118

119

120

121

122

123

124

125

126

larger than the right one. The middle portion of the left ovary was selected for histological

examination, andthe stages of maturity were classified into six phases according to Sun (1985).

Both ovaries were removed and weighed to the nearest $0.0001 \mathrm{~g}\left(\mathrm{~W}_{\mathrm{G}}\right)$, and the GSI was

calculated as follows:

$\mathrm{GSI}=100 \mathrm{~W}_{\mathrm{G}} /\left(\mathrm{W}_{\mathrm{B}^{-}}-\mathrm{W}_{\mathrm{G}}\right)$.

The number of oocytes (both pre-vitellogenic and vitellogenic oocytes) from dissected ovaries was counted in December and January. Two sub-samples of tissue weighing approximately $0.1 \mathrm{~g}$ were taken from the middle section of each ovary and preserved in 5\% formalin. The oocyte counts in these two sub-samples were determined using a dissecting microscope and were used to estimate fecundity if the coefficient of variation of $\mathrm{N}$ per unit ovary weight was below $5 \%$ for the two sub-samples. The total fecundity $\left(F_{\mathrm{A}}\right)$ and relative fecundity $\left(F_{\mathrm{R}}\right)$ were calculated in January as follows:

$F_{\mathrm{A}}=\sum C \mathrm{n} W_{\mathrm{O}} \mathrm{n} / W_{\mathrm{S}} \mathrm{n}$ and $F_{\mathrm{R}}=100 F_{\mathrm{A}} / W_{\mathrm{B}}$

where $C \mathrm{n}$ is the counted number of eggs in sub-sample $\mathrm{n}, W_{\mathrm{O}} \mathrm{n}$ is the corresponding ovary weight, $W$ sn is the sub-sample weight and $\mathrm{n}$ is the number of subsamples.

To reveal the oocytes developed synchronously or asynchronously and the spawning pattern, the oocyte diameters frequencies were plotted. The Mann-Whitney U test was used to compare the developmental stages of gonads between the upper and lower modal groups in the same cohort within the maturing season. The difference in GSI between November, December, and January, as well as the difference in fecundity between December and January, was tested using analysis of covariance (ANCOVA) with WB as the covariate. Differences in GSI, fecundity, and 
127 relative fecundity between the upper and lower modal groups in January were examined using

128 one-way analysis of variance (ANOVA). All statistical analyses were conducted using

129 STATISTICA 12.0 (StatSoft, Tulsa, OK, USA). P $<0.05$ was considered significant.

131 Analysis of cannibalism

$132 \quad$ P. chinensis are translucent, allowing for gross examination of gut contents and visual

133 identification of cannibalism in individuals. We chose to dissect cannibals with visible prey in

134 their guts. Cannibals and prey were examined for SL (to the nearest $1 \mathrm{~mm}$ ). The prey to cannibal

135 size ratios in about 20 cases were calculated for each month from July through December.

Results

Growth and intra-cohort size divergence

Two cohorts of $P$. chinensis were identified during the sampling period. Individuals collected in March 2010 belonged to the 2009 cohort and the individuals sampled after March 2010 belonged to the 2010 cohort. Samples collected in March 2010 ranged in SL from 81 to 225 $\mathrm{mm}$ and consisted of reproductive females and males from the 2009 cohort. $P$. chinensis juveniles belonging to the 2010 cohort were sampled from May 2010 onwards, and the SL

144 distribution pattern was unimodal until early July, when a bimodal length distribution began to emerge and lasted through January 2011. From November to January, the reproductive

146 population could be divided into the lower modal group (SL $<120 \mathrm{~mm}$ ) and upper modal group

147 (SL>120 mm) on the basis of size (Fig. 2). The population sampled in February and March did 
148

149

150

151

152

153

154

not exhibit a bimodal distribution because the fish died after spawning.

Characteristics of cannibals and prey

Cannibalism was first observed in July. The SL of cannibals sampled during this month ranged from 65 to $91 \mathrm{~mm}$, while those of prey ranged from 38 to $52 \mathrm{~mm}$. Both cannibals and prey grew larger over time. The cannibals generally reached a SL of $>120 \mathrm{~mm}$ by November, and the prey were usually smaller than $120 \mathrm{~mm}$ (Table 1). Given that the reproductive population in November could be divided into two size groups by SL with $120 \mathrm{~mm}$ as the cutoff (Fig. 2), it is apparent that the upper modal group was comprised of cannibals and the lower modal group was comprised of the prey. The prey to cannibal size ratio ranged from 0.47 to 0.67 (Table 1).

\section{Examination of sex ratio}

The sex of all sampled individuals was determined from early October 2010 to early March 2011. Monthly observations of sex ratios (male to female) did not differ from parity (1:1) from October through January $(\mathrm{P}=0.808,0.410,0.563,0.621$, respectively $)$ or vary significantly among months $\left(\mathrm{x}^{2}=1.499, \mathrm{df}=3, \mathrm{P}=0.683\right)$. However, the sex ratios in February and March were 13.4 and 18.1, respectively, due to natural mortality of females after spawning (Fig. 3). The remaining population mainly consisted of males in the lower modal group (Fig. 2). From October through January, sex ratios did not differ from parity in the upper modal group $(\mathrm{P}=0.453,0.450$, 0.475, 0.527, respectively) or the lower modal group $(\mathrm{P}=0.462,0.409,0.428,0.635$, respectively). 
170 Gonad development and the differences between the two groups

Oocytes developed asynchronously in ovaries of $P$. chinensis; pre-vitellogenic (Phase III \&

II) oocytes and vitellogenic (Phase IV \& V) oocytes existed in the same ovary. The gonads of

173

174

175

176

177

178

179

180

181

182 female $P$. chinensis did not develop to stage II until early October, after which they developed quickly to stage III in the first half of October. In early November, individuals in stages III and IV of gonadal development accounted for $61.5 \%$ and $38.5 \%$ of the female population, respectively. A few oocytes developed to stage $\mathrm{V}$ at the beginning of December, but all the oocytes in an ovary did not develop synchronously to the same stage. Most female gonads developed to stage IV or V and the fish could spawn in early January, but only a few postspawning individuals were sampled in February and March (Fig. 4). The oocytes developed asynchronously, and oocytes of different developing phases may commonly occur in the same ovary of maturing females (Fig.5). Most female gonads developed to stage III or IV in early November, and females in the upper modal group seemed to mature faster than those in the lower modal group, although this difference was not significant $(Z=-1.117, P=0.239)$. In early December, females in maturity stage IV accounted for the largest proportion both in the upper $(88.5 \%)$ and lower modal groups $(81.5 \%)$, and the maturity stage distribution was not significantly different between the groups $(Z=-1.401, P=0.161)$. In early January, almost all of the female gonads developed to stage IV or $\mathrm{V}$, and no significant differences were observed in the developmental rates between the groups $(Z=-1.934, P=0.053)$ (Fig. 6). 
190

191

192

193

194

195

196

197

198

199

200

201

202

203

204

205

206

207

208

209

Spawning pattern

Oocytes diameter distribution pattern was bimodal in December(Fig.7a), which indicated that the oocytes developed asynchronously. However, the distribution pattern was unimodal in January(Fig.7b). Results of the ANCOVA (BW as the covariate) also revealed no significant difference in fecundity between early December and early January $(F 2,110=3.4, P=0.067)$. In other words, there was no down-regulation of fecundity during gonad development or indeterminate spawning. Therefore, $P$. chinensis is a semelparous fish although the oocytes developed asynchronously.

Differences in reproductive investment between the groups

The GSI increased dramatically from November to January, ranging from 1.8 to $10.2 \%$ in November, 2.9 to $44.1 \%$ in December, and 7.6 to $76.4 \%$ in January (Fig. 8). Results of the ANCOVA (BW as the covariate) indicated that the differences in GSI among the three months were all significant $(\mathrm{F} 2,161=185.3, \mathrm{P}<0.001)$. The GSI of fish in the upper modal group was significantly higher than that of fish in the lower modal group in November (ANOVA, F1,50 = 56.3, $\mathrm{P}<0.001$ ), December (ANOVA, F1,51 = 50.0, $\mathrm{P}<0.001)$, and January (ANOVA, F1,57 = 95.1, $\mathrm{P}<0.001)$ (Fig. 8).

Samples from January were used to analyze intra-population divergence of fecundity. Fecundity ranged from 1,592 to 36,705 eggs, and relative fecundity ranged from 500 to 1,646 eggs per gram BW. The relative and absolute fecundity were significantly higher in females from 
210 the upper modal group than those in the lower modal group (ANOVA, F1,57 $=121.5, \mathrm{P}<0.001$

211 and ANOVA, F1,57 = 21.94, P <0.001, respectively) (Fig. 9).

212

213

\section{Discussion}

214 Piscivorous, cannibalism and size divergence

215 Size variation among clearhead icefish populations has been previously reported (Zhu 1985;

216 Wang and Jiang 1992; Tang et al. 2003). Xie et al. (2001) noted two peaks within the size

217 frequency distribution of a reproductive population. However, this is the first report of within-

cohort bimodal size distribution in $P$. chinensis. Bimodal size distribution is well documented in

iteroparous fishes (Huss et al. 2010; Alejo-Plata et al. 2011), and studies on Percidae species

revealed diet shift contributing to the size divergences in YOY fish, and that the extreme growth

of the upper modal group was induced by piscivory (cannibalism) (Frankiewicz et al. 1996; Post

2003; Urbatzka et al. 2008). The synchronous investigation on diet composition showed that a

few bigger individuals of $P$. chinensis began to feed on fish and cannibalism also occured in

early July, and then piscivory and cannibalism accompanied the size bimodal pattern forming

(Tang et al. 2013). And the victims of cannibalism accounted for the majority of the diet of

cannibals in December and January (Tang et al. 2013).

Fitness of the cannibals

The absolute and relative fecundity reported in the present study for a population of $P$.

chinensis in Lake Khanka shows wider range (1,592 - 36,705 eggs, and 500 - 1,646 eggs/gram- 
231 BW) than populations from other locations (3,295 to 34,520 eggs, and 340 to 1,290 eggs/gram-

232 BW) (Zhang et al. 1981; Xie et al. 2001). While there is no published information illustrating the

233 difference in reproductive investment between the two modal groups of clearhead icefish, this

234 investigation demonstrates that the reproductive investment of females belonging to the upper

235 modal group(cannibals) was significantly higher than that of females from the lower modal

236 group(victims) in terms of GSI, absolute fecundity and relative fecundity. In common, larger fish

237 has higher absolute fecundity and lower relative fecundity than the smaller conspecifics. $P$.

238 chinensis cannibals have both higher absolute fecundity and relative fecundity than the victims,

239 which means piscivory and cannibalism increased reproductive potential greatly. In addition, the

240 cannibals grow faster and become bigger than the potential victims, which will increase their

241 survival rate undoubtedly.

243 Gonad development and spawning pattern

244 Researchers have offered multiple theories to describe the reproductive strategy of $P$.

245 chinensis. Sun (1985) reasoned that $P$. chinensis spawn twice during their lifetime upon

246 examination of their gonad histology, but Xu et al. (2000) determined that this species spawns

247 once before death. Xie et al. (2001) theorized that $P$. chinensis can spawn once or multiple times.

248 Our research supports the theory that $P$. chinensis exhibits a semelparous reproductive strategy,

249 although oocytes developed asynchronously in the same gonad. This is different from other

250 semelparous species such as chum salmon Oncoryhchus keta (Crozier et al. 2008) and Sea

251 lamprey Petromyzon marinus(Mcbride et al. 2015). The asynchronous development of oocytes 
252 should be attributed to the relatively rather high fecundity and the nutrition may not be enough to 253 develop all the oocytes at the same time, which is a mechanism to produce as many eggs as 254 possible in a spawning event in a life time.

255

256 Sex ratio and mate selectivity

257 Sex ratios did not differ from parity before spawning (October through December) or during 258 spawning (primarily early to mid-January) in both the upper modal and lower modal groups. This is similar to reports for this species from other locations (Zhang et al. 1981; Sun and Zhou 1989; Xu et al. 2000; Xie et al. 2001). However, we found that the reproductive population was mainly composed of males in the lower modal group after January. We hypothesize that males in the lower modal group have a reduced opportunity to participate in spawning. The intra-cohort sex selectivity of $P$. chinensis may influence evolution towards early birth and faster growth, although this theory requires further study.

Life history strategy

The $P$. chinensis is a small fish that matures early with a short life span and relatively high

fecundity. This makes it an exception from the three-point life-history continuum model

proposed by Winemiller and Rose (1992). Larger individuals (upper modal group) tend to exhibit an opportunistic life-history strategy, but characterized by relatively higher fecundity. An opportunistic colonization strategy facilitates range expansion of an invading species through 
273

274

275

276

277

278

279

280

281

282

283

284

285

286

287

288

289

290

291

292

293

2009). Exceptional higher fecundity would undoubtedly contribute to rapid increase in

population size and spread of the opportunistic fish, $P$. chinensis.

\section{Conclusion}

Transition to feed on fish increased the investment of the female $P$. chinensis and may also increase the fitness of male in reproductive competing. This research provided a direct evidence that transition to be carnivorous is positively significant in evolution, although further study on increasing the fitness of male $P$. chinensis need to be conducted.

\section{References}

Alejo-Plata C, Díaz-Jaimes P, Salgado-Ugarte IH, 2011. Sex ratios, size at sexual maturity, and spawning seasonality of dolphinfish (Coryphaena hippurus) captured in the Gulf of Tehuantepec, Mexico. Fisheries Research 110: 207-216.

Buijse AD, Houthuijzen RP, 1992. Piscivory, growth, and size-selective mortality of age 0 pikeperch (Stizostedion lucioperca). Canadian Journal of Fisheries and Aquatic Sciences 49: 894-902.

Crozier LG, Hendry AP, Lawson PW, Quinn TP, Mantua NJ, Battin J, Shaw RG, Huey RB, 2008. Potential responses to climate change in organisms with complex life histories: evolution and plasticity in Pacific salmon. Evolutionary Applications 2:252-270. DOI: 10.1111/j.1752-4571.2008.00033.x

Fox MG, Vila-Gispert A, Copp GH, 2007. Life-history traits of introduced Iberian pumpkinseed Lepomis gibbosus relative to native populations. Can differences explain colonization 

success? Journal of Fish Biology 71(Suppl D):56-69.

295

296

297

298

299

300

301

302

303

304

305

306

307

308

309

310

311

312

313

314

Frankiewicz P, Dabrowski K, Zalewski M, 1996. Mechanism of establishing bimodality in a size distribution of age-0 pikeperch, Stizostedion lucioperca (L.) in the Sulejow Reservoir, Central Poland. Annales Zoologici Fennici 33:321-327.

Heermann L, Scharf W, van der Velde G, Borcherding J, 2014. Does the use of alternative food resources induce cannibalism in a size-structured fish population? Ecology of Freshwater Fish 23(2):129-140.

Huss M, Kooten VT, Persson L, 2010. Intra-cohort cannibalism and size bimodality: a balance between hatching synchrony and resource feedbacks. Oikos 119:2000-2011.

Mcbride RS, Somarakis S, Fitzhugh GR, Albert A, Yaragina NA, Wuenschel MJ, AlonsoFernandez A, Basilone G, 2015. Energy acquisition and allocation to egg production in relation to fish reproductive strategies. Fish and Fisheries 16(1):23-57.

Post DM, Kitchell JF, Hodgson JR, 1998. Interactions among adult demography, spawning date, growth rate, predation, overwinter mortality, and the recruitment of largemouth bass in a northern lake. Canadian Journal of Fisheries and Aquatic Sciences 55:2588-2600.

Post DM, 2003. Individual variation in the timing of ontogenetic niche shifts in largemouth bass. Ecology 84:1298-1310.

Ribeiro F, Collares-Pereira MJ, Moyle PB,2009. Non-native fish in the fresh waters of Portugal, Azores and Madeira Islands: a growing threat to aquatic biodiversity. Fisheries Management and Ecology 16:255-264.

Saruwatari T, Oohara I, Kobayashi T, 2002. Salangid fishes: their past, present and future. 
Fisheries Science 68(Suppl 1):71-74.

316 Sun G, 1985. On the maturity of the female gonads and the type of spawning of the ice fish. Journal of fisheries of China 9:363-368. (In Chinese with an English abstract).

Sun G, Zhou Z, 1989. A preliminary study of ecology of Protosalanx chinensis in Yangtze River abstract).

Werner EE, Gilliam JF, 1984. The ontogenetic niche and species interactions in size-structured 
populations. Annual review of ecology and systematics 15:393-425.

337

338

339

340

341

342

343

344

345

346

347

348

349

350

351

352

353

354

355

Winemiller KO, Rose KA, 1992. Patterns of life history diversification in North American fishes: implication for population regulation. Canadian Journal of Fisheries and Aquatic Science 49:2196-2218.

Xie H, Tang Z, Xie Y, Li B, Li X, Yuan F, Duan K, Sun Y, 2001. Aspects of repoductive biology of large icefish ( Protosalanx chinensis) in Shuifeng Reservoir. J Dalian Fish Univ 2:79-86. (In Chinese with an English abstract).

Xie Y, Xie H, 1997. Classification, Distribution, and Population Ecology of Salangidae Fishes. Chinese Journal of Fisheries 10:11-19. (In Chinese with an English abstract).

Xu M,Wu H, Liu Y, Zhang L, 2000. Biological effect of transplanting Protosalanx chinensis in Guandaohe reservoir (III) : Propagation behavior. J Lake Sci 1:94-96 (In Chinese with an English abstract).

Zhang K, Zhuang D, Zhang L, Gao C, Zhang J, Xu A, 1981. On the Protosalanx chinensis and its propagation in Hongze Lake. J Fish Chin 1:29-39. (In Chinese with an English abstract).

Zhu C, 1985. A preliminary study on growth and feeding habits of icefish in Taihu Lake. Journal of Fisheries of China 3:275-287. (In Chinese with an English abstract). 
Figure 1

Location of Lake Khanka (China/Russia) and sampling site.

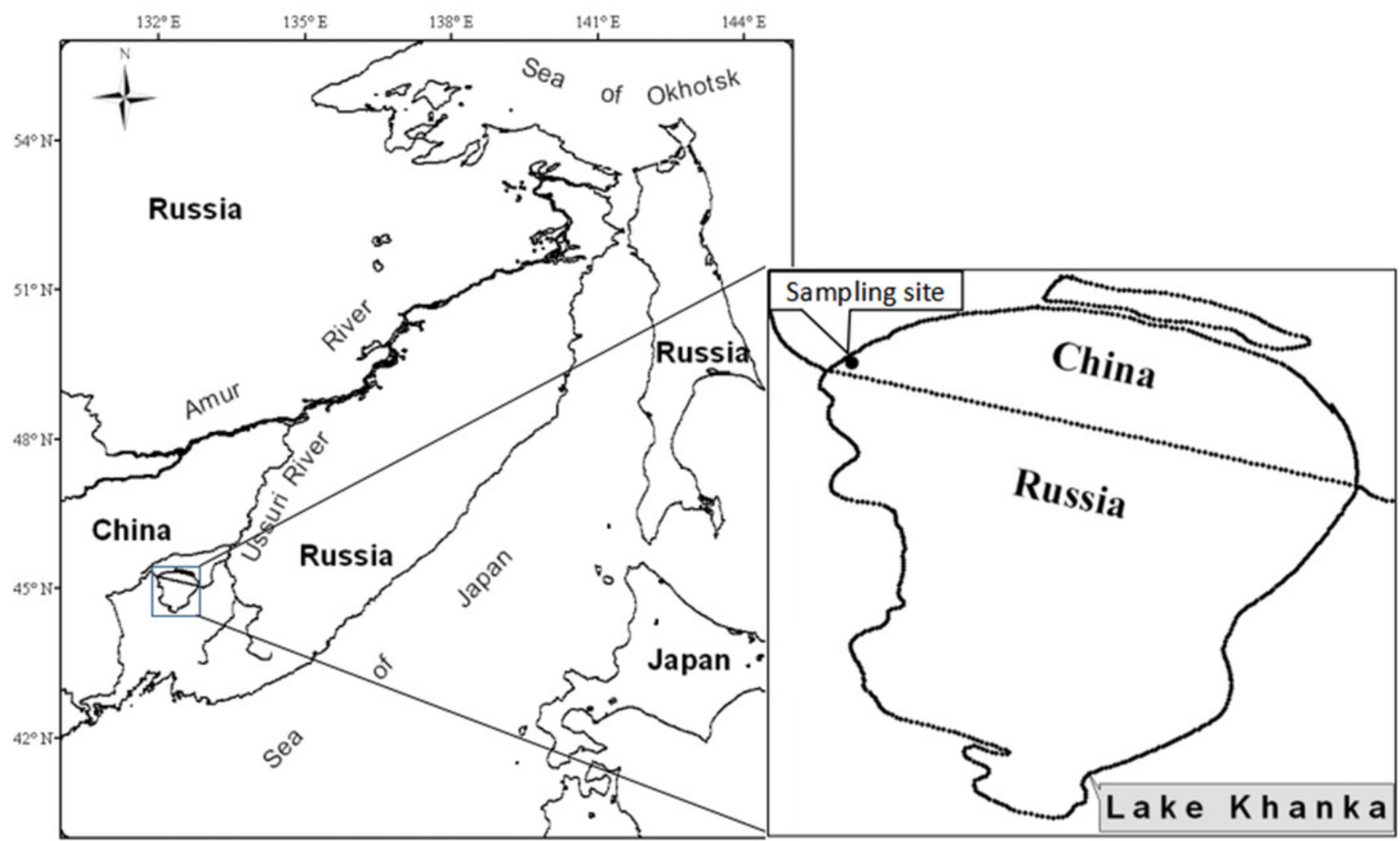




\section{Figure 2}

. Standard length frequency distribution of $P$. chinesis in Lake Khanka from March 2010 through March 2011. The solid line connects lower modal groups and the dashed line connects upper modal groups.

A, Cohort born in 2009; B-L, Cohort born in 2010. Jan, January; Feb, February; Mar, March; Jun, June; Jul, July; Aug, August; Sep, September; Oct, October; Nov, November; Dec, December. 

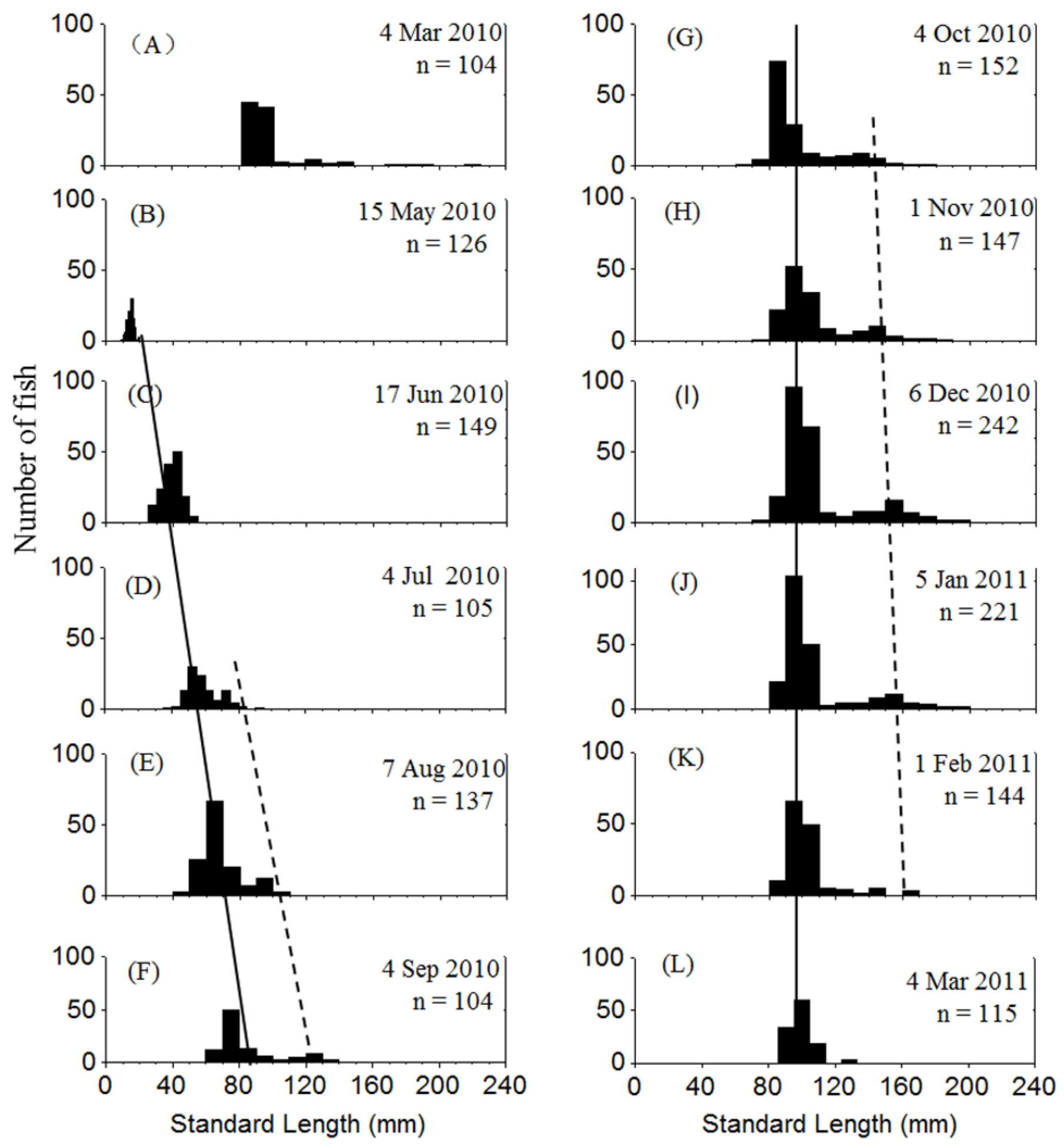


\section{Figure 3}

Monthly sex ratio variation from 4 October 2010 through 4 March 2011.

Oct, October; Nov, November; Dec, December; Jan, January; Feb, February; Mar, March.

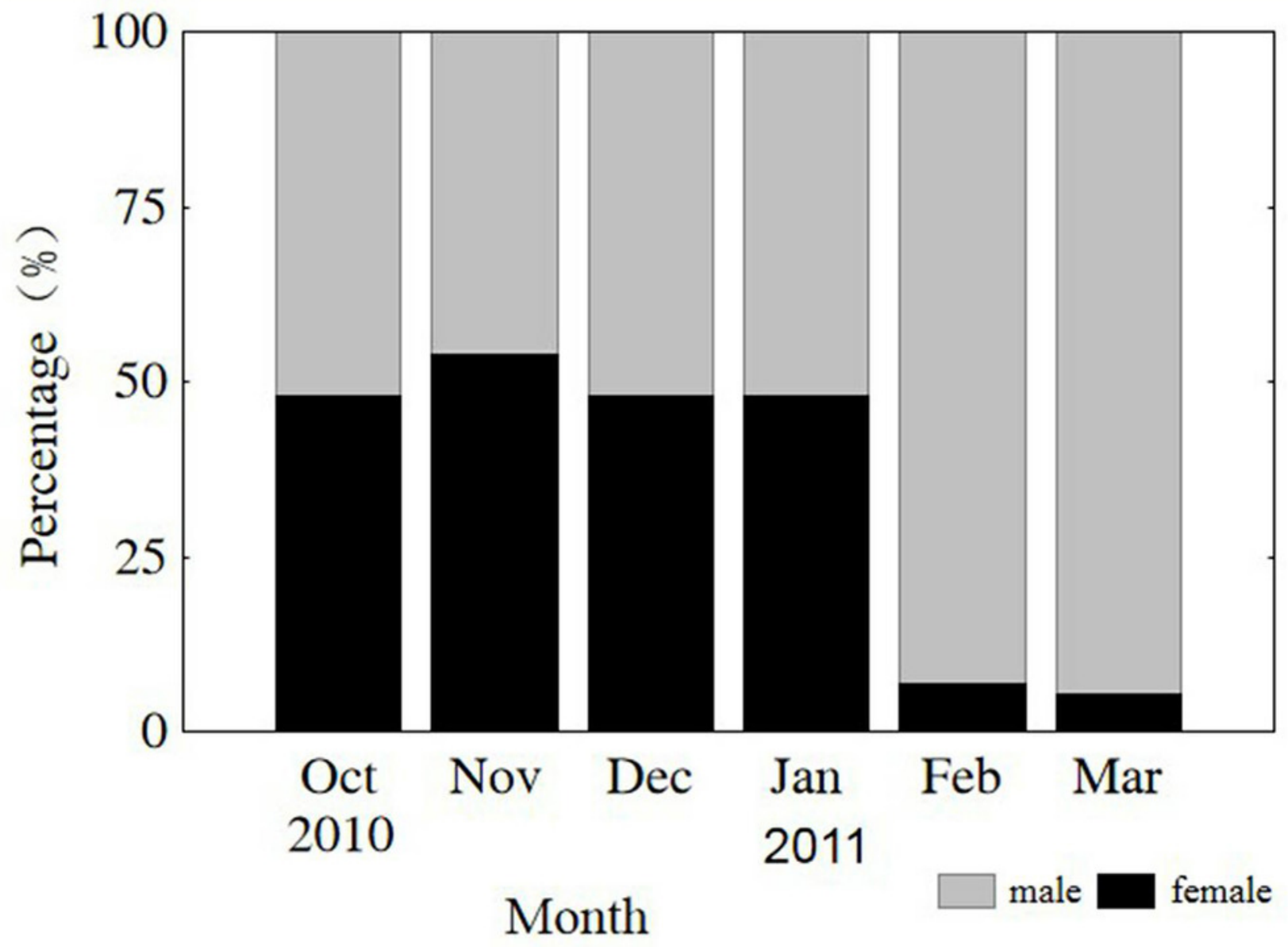


Figure 4

Percentage of $P$. chinesis at different ovarian maturity stages from early October through early March.

Gonad maturity stage: white, I; crossed, II; vertical lines, III; horizontal lines, IV; diagonal lines, V; black, VI. S, September; O, October; N, November; D, December; J, January; F, February; M, March.

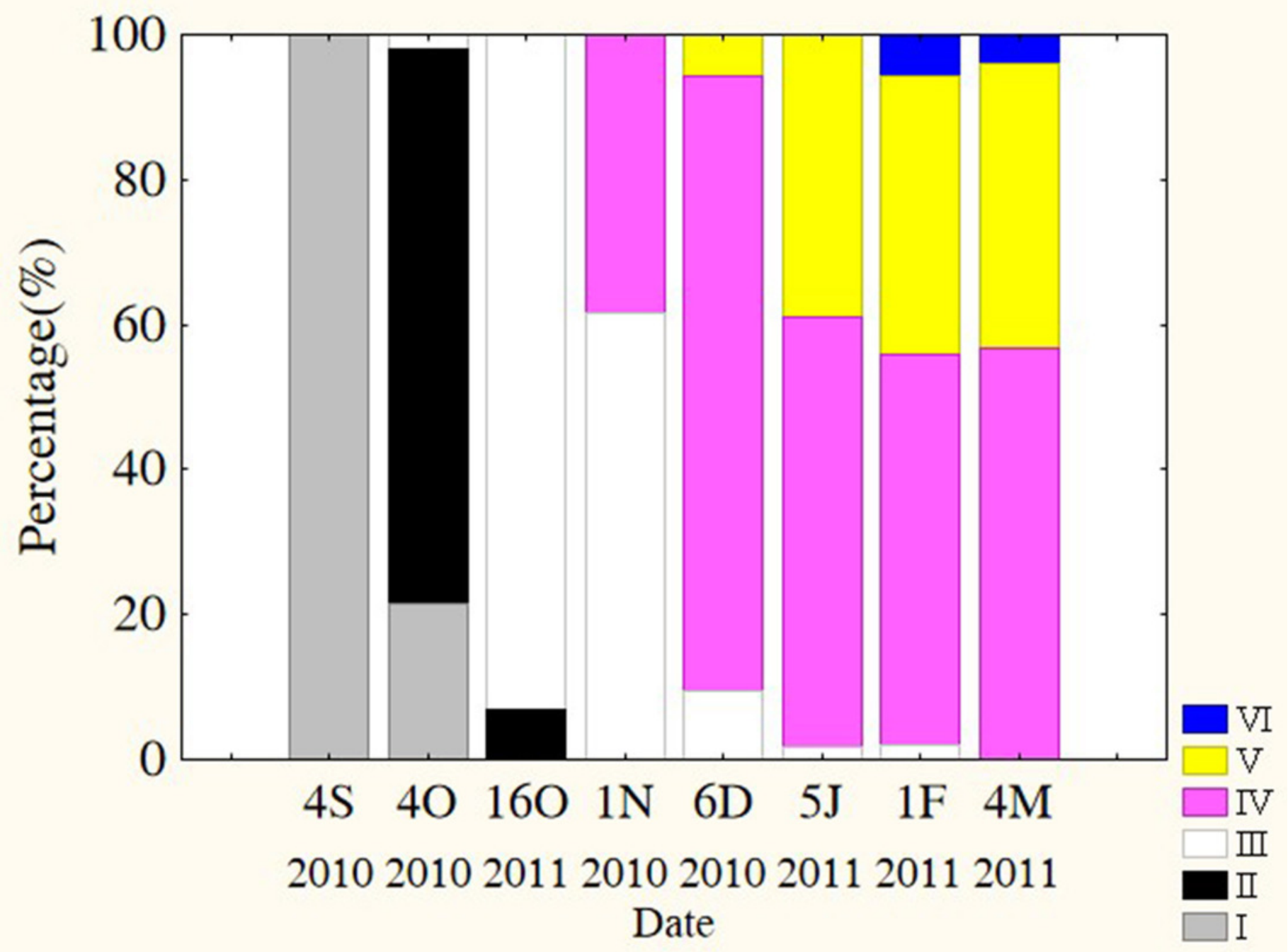




\section{Figure 5}

The asynchrony of oocytes development of $P$. chinensis.

Cross-section of ovary (a) and egg micrograph (b) of a fish in November (SL,145mm;

BW, 16.64g); cross-section of ovary (c) and egg micrograph (d) of a fish in January

(SL,180mm; BW, 26.15g): (—) Phase II (Perinucleolar) oocyte; ( $($ ) Phase III (Yolk vesicle) oocyte; $(\rightarrow$ ) Phase IV (Yolk) oocyte; $(\uparrow)$ Pre-vitellogenic (Phase II\&lII) oocyte; $(\downarrow)$ Phase V (migratory nucleus) oocyte. Scale bar $=1 \mathrm{~mm}$.
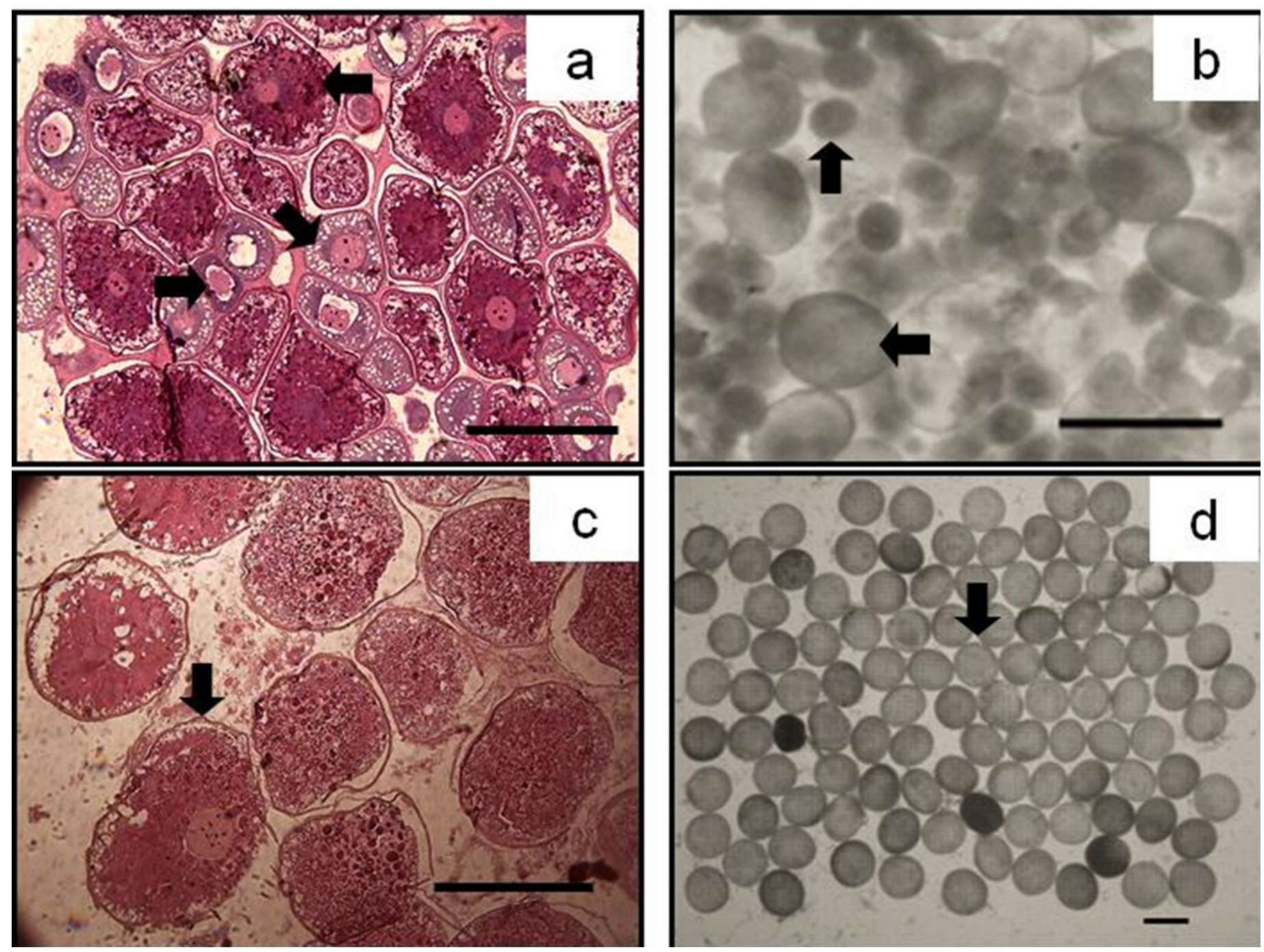
Figure 6

Percentage of $P$. chinesis females with different ovarian maturity stages in early November, December 2010 and January 2011 from the lower modal group $(a, S L<120$ $\mathrm{mm}$ ) and upper modal group (b, SL > $120 \mathrm{~mm}$ ). 

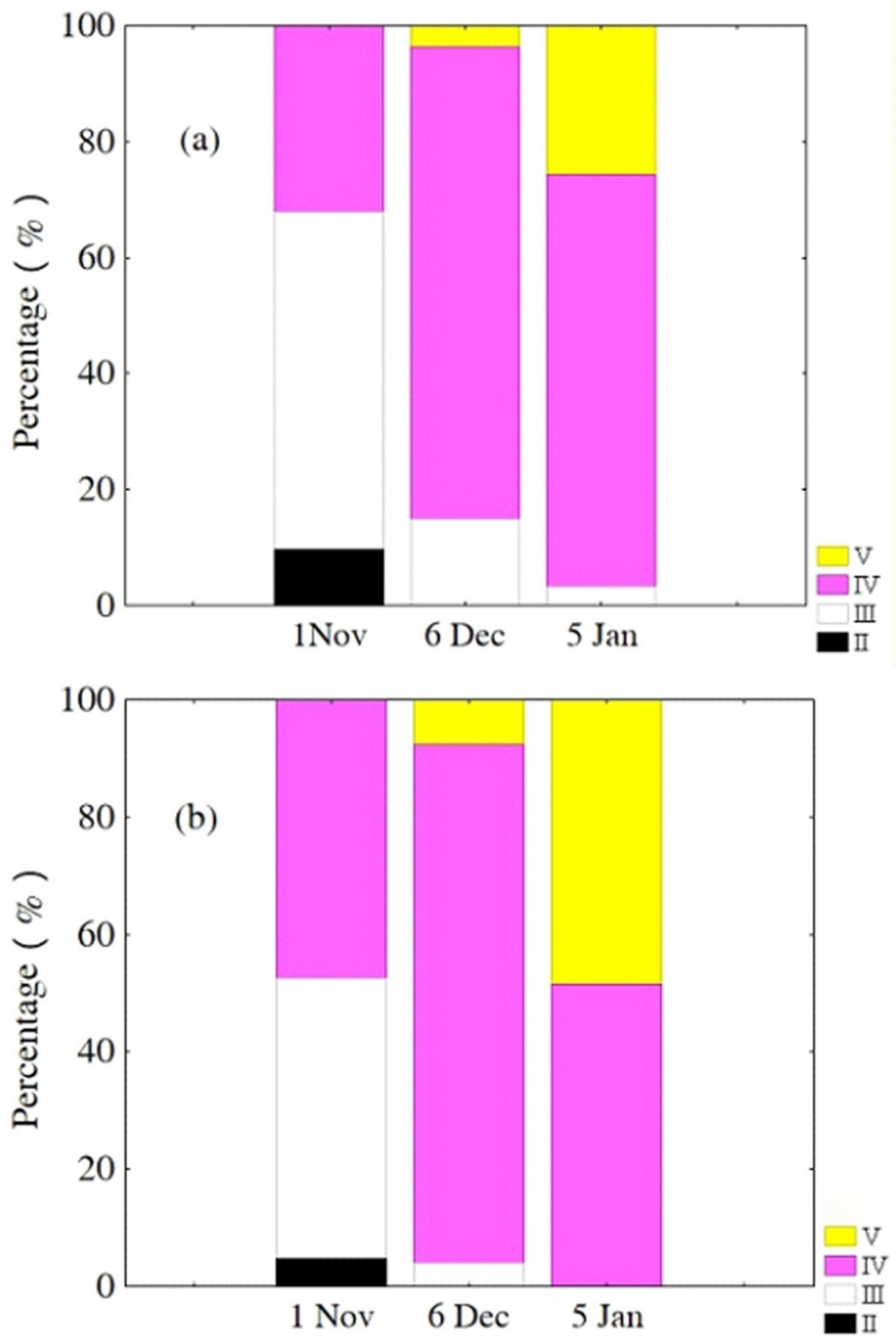
Figure 7

Oocytes development in December $\square$ a $\square$ and January $\square \mathrm{b} \square$ 

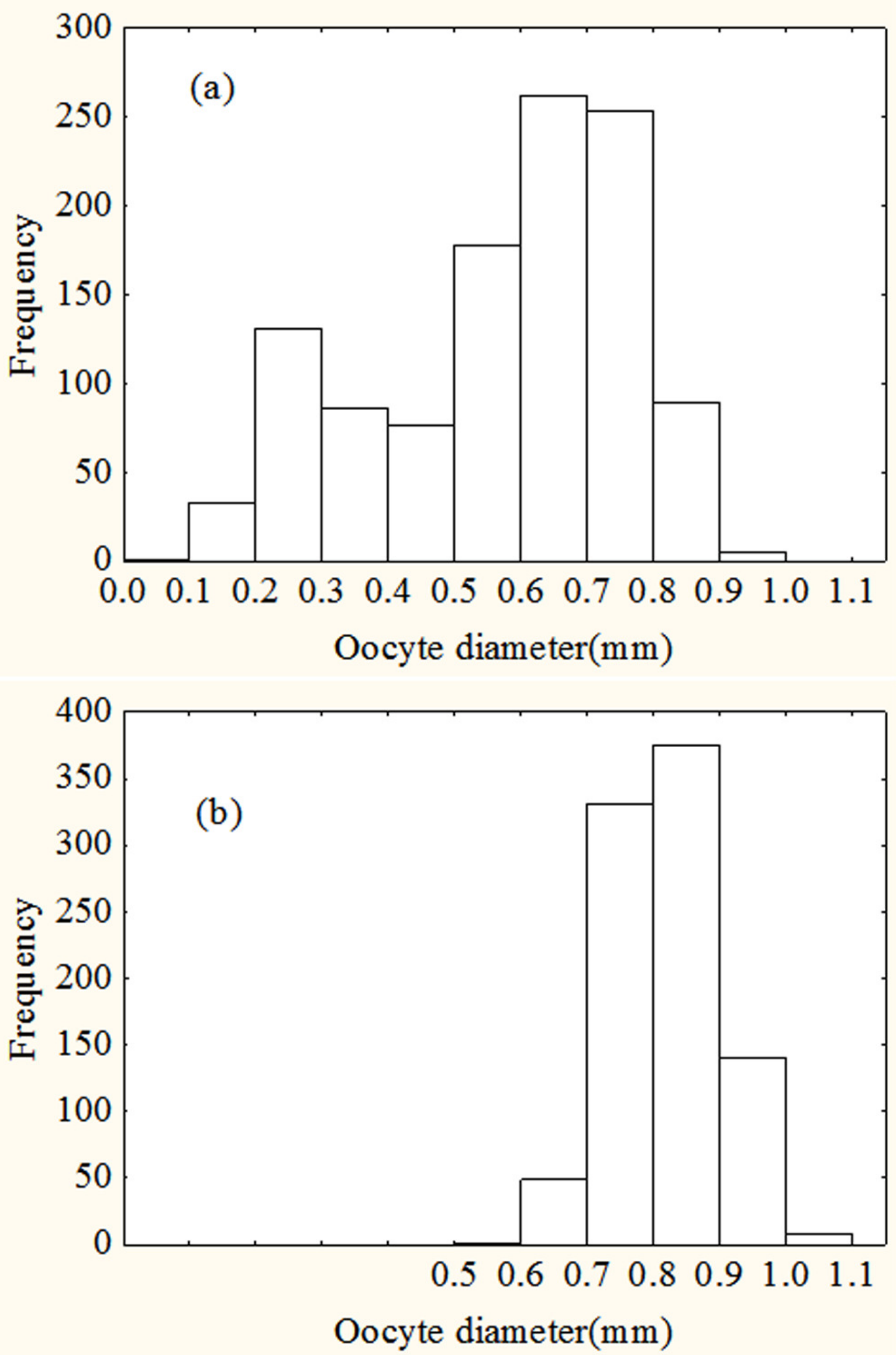
Figure 8

Intra-population variation in gonadosomatic index (GSI) in November 2010(a), December 2010(b) and January 2011(c).

$S L=$ standard length. 


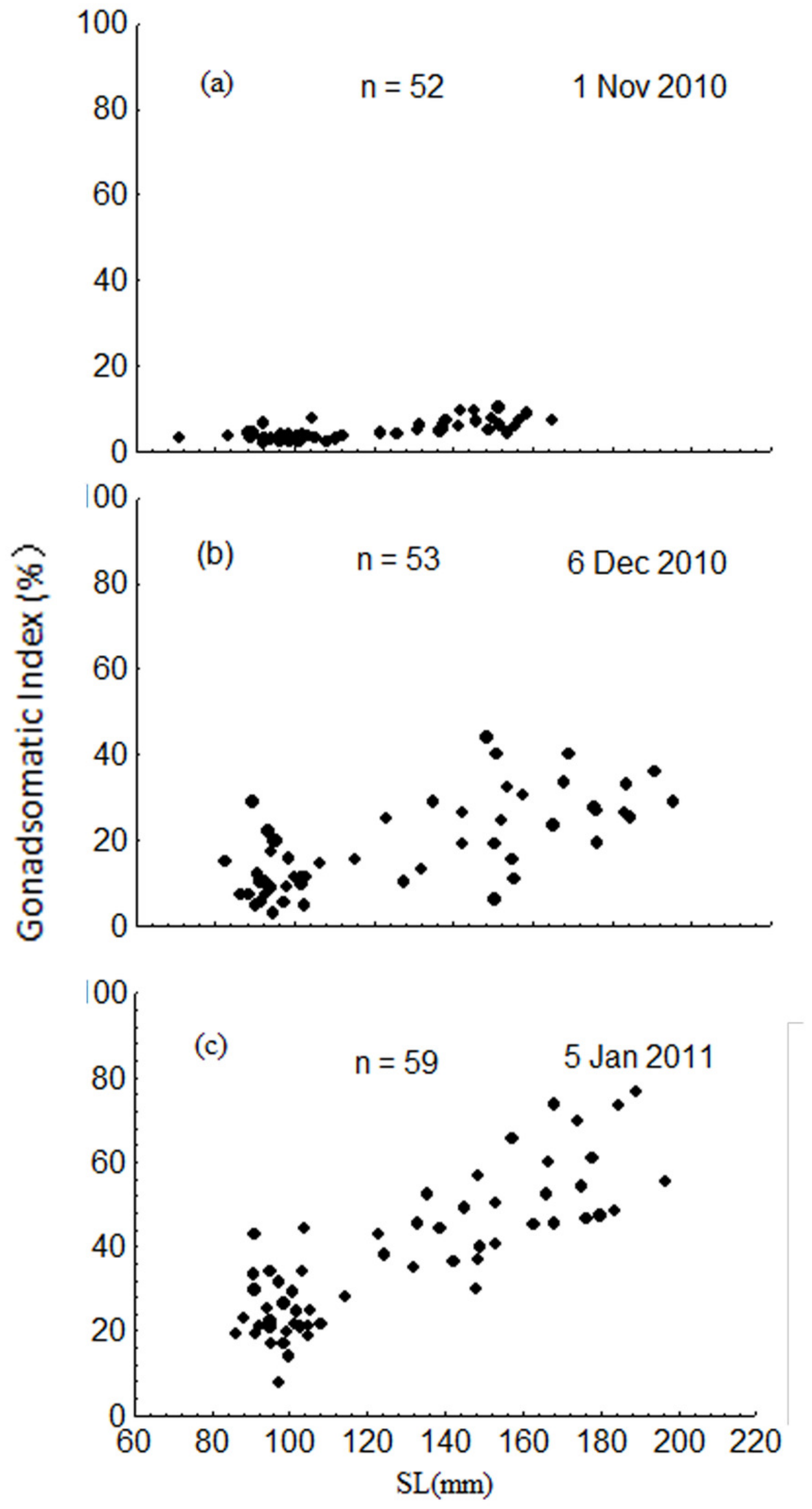


Figure 9

Absolute fecundity(a) and relative fecundity (b) of $P$. chinesis females sampled in January.

$S L=$ standard length 

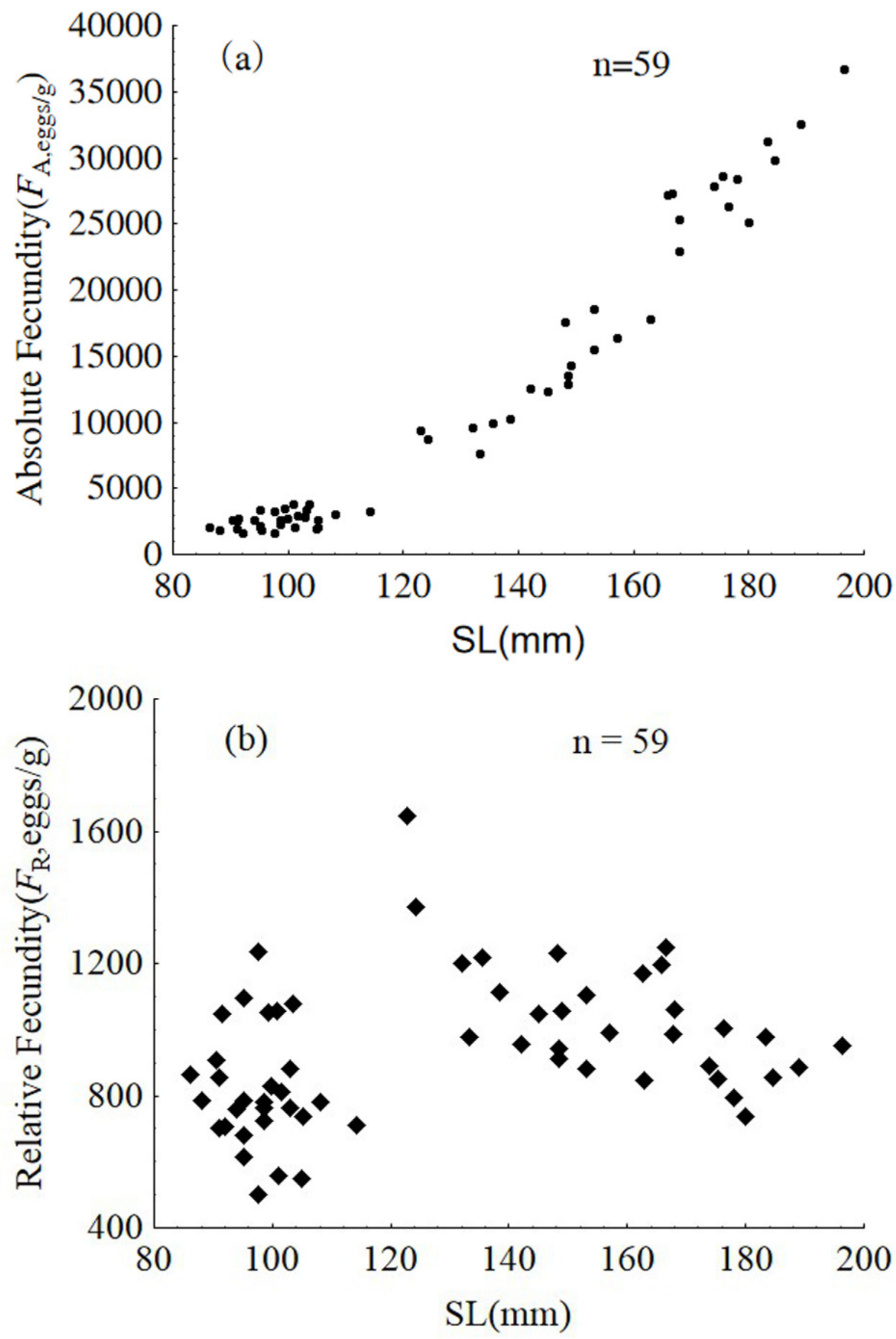


\section{Table $\mathbf{1}$ (on next page)}

Differences in mean standard lengths $(\mathrm{SL}) \pm$ standard deviation (SD) between $P$. chinensis cannibals and prey.

Jul, July; Aug, August; Sep, September; Oct, October; Nov, November; Dec, December. 
1 Placement of Table 1: Page 9

2

\begin{tabular}{|c|c|c|c|c|c|c|c|}
\hline \multirow{2}{*}{ Month } & \multirow{2}{*}{$\mathrm{N}$} & \multicolumn{2}{|c|}{ SL of cannibals (mm) } & \multicolumn{2}{|c|}{ SL of the prey $(\mathrm{mm})$} & \multicolumn{2}{|c|}{ SL of the prey / SL of cannibals } \\
\hline & & Range & Mean (S.D.) & Range & Mean (S.D.) & Range & Mean (S.D.) \\
\hline Jul & 24 & $65-91$ & $76 \pm 7.2$ & $38-52$ & $48 \pm 6.2$ & $0.54-0.65$ & $0.63 \pm 0.02$ \\
\hline Aug & 25 & $72-110$ & $89 \pm 13.5$ & $46-59$ & $51 \pm 4.9$ & $0.47-0.64$ & $0.57 \pm 0.05$ \\
\hline Sep & 29 & $108-146$ & $128 \pm 9.5$ & $55-75$ & $65 \pm 5.5$ & $0.48-0.54$ & $0.51 \pm 0.02$ \\
\hline Oct & 31 & 119-177 & $139 \pm 16.1$ & $72-102$ & $83 \pm 8.6$ & $0.49-0.67$ & $0.60 \pm 0.05^{\mathrm{a}}$ \\
\hline Nov & 27 & $122-189$ & $147 \pm 15.7$ & $71-115$ & $88 \pm 10.2$ & $0.51-0.65$ & $0.60 \pm 0.03$ \\
\hline Dec & 35 & $123-196$ & $153 \pm 16.7$ & $82-117$ & $93 \pm 9.6$ & $0.50-0.70$ & $0.61 \pm 0.04$ \\
\hline
\end{tabular}

